This is an electronic reprint of the original article. This reprint may differ from the original in pagination and typographic detail.

Author(s): Hietavala, Enni-Maria; Stout, Jeffrey R.; Frassetto, Lynda A.; Puurtinen, Risto;

Pitkänen, Hannu; Selänne, Harri; Suominen, Harri; Mero, Antti

Title: $\quad$ Dietary acid load and renal function have varying effects on blood acid-base status and exercise performance across age and gender

Year: $\quad 2017$

Version:

Please cite the original version:

Hietavala, E.-M., Stout, J. R., Frassetto, L. A., Puurtinen, R., Pitkänen, H., Selänne, H., Suominen, H., \& Mero, A. (2017). Dietary acid load and renal function have varying effects on blood acid-base status and exercise performance across age and gender. Applied Physiology, Nutrition and Metabolism, 42(12), 1330-1340.

https://doi.org/10.1139/apnm-2017-0279

All material supplied via JYX is protected by copyright and other intellectual property rights, and duplication or sale of all or part of any of the repository collections is not permitted, except that material may be duplicated by you for your research use or educational purposes in electronic or print form. You must obtain permission for any other use. Electronic or print copies may not be offered, whether for sale or otherwise to anyone who is not an authorised user. 


\title{
Dietary acid load and renal function have varying effects on blood acid-base status and exercise performance across age and gender
}

\author{
Enni-Maria Hietavala ${ }^{1}$, Jeffrey R. Stout ${ }^{2}$, Lynda A. Frassetto ${ }^{3}$, Risto Puurtinen ${ }^{1}$, Hannu \\ Pitkänen ${ }^{4}$, Harri Selänne ${ }^{5}$, Harri Suominen ${ }^{6}$, Antti A. Mero ${ }^{1}$
}

Corresponding author:

Enni-Maria Hietavala

E-mail address: enni.hietavala@jyu.fi

Mailing address: P.O. Box 35, 40014 University of Jyväskylä, Finland

${ }^{1}$ Biology of Physical Activity, Faculty of Sport and Health Sciences, University of Jyväskylä, P.O. Box 35, 40014 Jyväskylä, Finland (risto.j.puurtinen@jyu.fi, antti.a.mero@jyu.fi)

${ }^{2}$ Institute of Exercise Physiology and Wellness, University of Central Florida, P.O. Box 161250, FL 32816-1250, Orlando, Florida, USA (jeffrey.stout@ucf.edu)

${ }^{3}$ General Clinical Research Center, University of California San Francisco, 505 Parnassus

Avenue, San Francisco CA 94117, California, USA (1ynda.frassetto@ucsf.edu)

${ }^{4}$ Honka Holding, c/o Honkatarhat Oy, Kirkkokallio 20, 38950 Honkajoki, Finland (hannu.pitkanen@mykora.com)

${ }^{5}$ Department of Psychology, University of Jyväskylä, P.O. Box 35, 40014 Jyväskylä, Finland (harri.p.selanne@,jyu.fi)

${ }^{6}$ Health Sciences, Faculty of Sport and Health Sciences, University of Jyväskylä, P.O. Box 35, 40014 Jyväskylä, Finland (harri.k.suominen@jyu.fi) 


\section{Abstract}

Purpose: Diet composition influences acid-base status of the body. This may become more relevant as renal functional capacity declines with aging. We examined the effects of low (LD) versus high dietary acid load (HD) on blood acid-base status and exercise performance.

Methods: Participants included 22 adolescents (AD), 33 young adults (YA) and 33 elderly (EL), who followed a 7-day LD and HD in a randomized order. At the end of both diet periods the subjects performed a cycle ergometer test $(3 \times 10 \mathrm{~min}$ at $35 \%, 55 \%, 75 \%$, and (except EL) until exhaustion at $100 \%$ of $\mathrm{VO}_{2} \mathrm{max}$ ). At the beginning of, and after the diet periods, blood samples were collected at rest and after all workloads. $\mathrm{VO}_{2}, \mathrm{RER}$ and $\mathrm{HR}$ were monitored during cycling. Results: In YA and EL, bicarbonate $\left(\mathrm{HCO}_{3}{ }^{-}\right)$and base excess (BE) decreased over the HD period, and $\mathrm{HCO}_{3}{ }^{-}, \mathrm{BE}$ and $\mathrm{pH}$ were lower at rest after $\mathrm{HD}$ compared to LD. In YA and EL women, $\mathrm{HCO}_{3}{ }^{-}$and $\mathrm{BE}$ were lower at submaximal workloads after $\mathrm{HD}$ compared to LD. In YA women, the maximal workload was $19 \%$ shorter and maximal $\mathrm{VO}_{2}$, RER and HR lower after HD compared to LD.

Conclusions: Our data uniquely suggests that better renal function is associated with higher availability of bases, which may diminish exercise-induced acidosis and improve maximal aerobic performance. Differences in glomerular filtration rate between the subject groups likely explains the larger effects of dietary acid load in the elderly compared to younger subjects and in women compared to men.

Key words: Potential renal acid load, dietary acid load, acid-base status, glomerular filtration rate, aging, alkalinity, aerobic exercise 


\section{Introduction}

Diet composition is known to influence net endogenous acid production, which may further affect acid-base status of the body (Poupin et al. 2012). Dietary acid load can be estimated by calculating the potential renal acid load (PRAL) of foods, which represents the renal net acid excretion caused by a foodstuff (Remer et al. 2003). The digestion of meat, grain and some dairy products increases the acid load of the body. Fruits and vegetables, which contain organic anions (e.g. citrate, malate) metabolizable to bicarbonate, lower net acid load. Western diet typically contains large amounts of animal protein and grain products but only small amounts of vegetables and fruits, and leads to a net production of acids in the body (Adeva and Souto 2011). For elderly populations, the dietary acid load may be a particularly important issue as aging is associated with a decline in the renal functional capacity, which diminishes the accuracy and speed of the regulation of volume and composition of the body fluids (Bolignano et al. 2014). Glomerular filtration rate (GFR) decreases with aging and consequently, blood $\mathrm{HCO}_{3}{ }^{-}$ concentration and $\mathrm{pH}$ are regulated at lower levels (Frassetto and Sebastian 1996). Increased acidity of the body has been reported to associate negatively with kidney function, bone health and muscle mass. For example, in the study of Scialla et al. (2012), higher net endogenous acid production was significantly associated with a faster decline in GFR. Tabatabai et al. (2015) found out that lower plasma $\mathrm{HCO}_{3}{ }^{-}$was associated with higher rate of bone loss in 70 -year-old participants. In addition, Dawson-Hughes et al. (2008) came to the conclusion that higher intake of fruits and vegetables, which contain base-producing compounds and decrease net endogenous 
acid production, favored the preservation of muscle mass in men and women over 65 years of age.

In addition to the health issues, dietary acid load may play a role in exercise. Over the decades, many studies have reported the positive effects of sodium bicarbonate supplementation and some other ergogenic aids on blood buffering capacity and exercise performance (Krustrup et al. 2015, Wilkes et al. 1983). Surprisingly, there are only a few studies that have investigated the impact of diet composition on acid-base status and exercise performance (e.g. Baguet et al. 2011, Caciano et al. 2015, Greenhaff et al. 1987; for review see Applegate et al. 2017). Moreover, to the best of our knowledge, the effects of dietary acid load on acid-base status of the elderly have not been reported during exercise. Increasing hydrogen ion $\left(\mathrm{H}^{+}\right)$concentrations in blood and muscle during high-intensity exercise cause acidosis, which is thought to be one of the causes of fatigue (Lancha Junior et al. 2015, Robergs et al. 2004). A diet high in vegetables and fruits could have the potential to affect blood bicarbonate buffering capacity and physical performance by attenuating the exercise-induced acidosis. For example, sodium bicarbonate supplementation has been reported to improve performance both in short ( 1-2 min) (Mero et al. 2004, Van Montfoort et al. 2004) and longer ( 20 min) exercise performances (Oöpik et al. 2003). The main purpose of this paper was to find out if low dietary acid load (LD) and high dietary acid load (HD) have effects on blood acid-base status and exercise performance during submaximal and maximal aerobic cycling in adolescents, young adults, and the elderly. We hypothesized that a diet with high acid load increases acidity of the blood and age-related decline in renal function affects the responses in acid-base parameters both at rest and in exercise. 


\section{Materials and methods}

\section{Participants}

In total, 93 men and women were selected to participate in the present study. Subjects were recruited from three age groups: 12-15-year-old adolescents (AD), 25-35-year-old young adults (YA) and 60-75-year-old elderly (EL). To recruit the AD group, we visited the local sports clubs who were participating in ice hockey, figure skating, gymnastics and athletics. The YA and EL groups were recruited via e-mail lists. The subjects of YA group were mainly students in the local University and the community-dwelling EL subjects were recruited from the Ageing Program of the local University. All subjects of YA and EL were recreationally active (e.g. walking, jogging, cycling, resistance training 2-4 times per week) but they were not training for competitive purposes. In the beginning of the study, there were 14 boys and 10 girls in the AD group, 16 men and 19 women in the YA group and 17 men and 17 women in the EL group. Altogether five subjects were not able to finish the study. Baseline anthropometric characteristics of the subjects who completed the whole data collection are presented in Table 1. The subjects did not use any medication during the study period aside from two exceptions: women of YA were allowed to use contraceptive pills and in the EL groups medications for high blood pressure and high cholesterol were acceptable. Subjects whose body mass index was above $33 \mathrm{~kg} / \mathrm{m}^{2}$ or who had other medications were excluded from the study. The experimental diets were planned beforehand and volunteers who had any relevant food allergy were not able to participate. Ethical approval for the study was obtained from the Ethical Committee of the local University and the study was in accordance with the Helsinki Declaration. Before any data 
collection the subjects were informed of the purpose and the methods of the study and they signed a written informed consent. Additionally, the subjects completed a health questionnaire and the elderly subjects also completed a health examination that was performed by a physician.

\section{Baseline testing}

To determine the subjects' $\mathrm{VO}_{2}$ max and maximal workload at baseline (Test 1) an incremental cycle ergometer test was cycled with a microprocessor controlled, eddy current brake equipped ergometer (Ergoline ergometrics 800, D-72475, Bitz, Germany). For the AD group, the initial workload was $30 \mathrm{~W}$ and at each stage it was increased by $20 \mathrm{~W}$ for boys and by $15 \mathrm{~W}$ for girls. For YA, the initial workload was $50 \mathrm{~W}$ and at each stage it was increased by $25 \mathrm{~W}$ for men and by $20 \mathrm{~W}$ for women. For EL, the initial workload was $30 \mathrm{~W}$ and at each stage it was increased by $25 \mathrm{~W}$ for men and $20 \mathrm{~W}$ for women. The subjects were advised to select a comfortable pedaling cadence between 60 and $90 \mathrm{rpm}$ and to maintain it for the duration of the test. In the AD and YA groups, the workload was increased every 2 min until volitional exhaustion occurred. $\mathrm{VO}_{2} \max$ was determined to be the highest $30-\mathrm{S} \mathrm{VO}_{2}$ value during the test and coincided with at least two of the following three criteria: a) $90 \%$ of age-predicted maximum heart rate; b) respiratory exchange ratio $>1.1$; and/or (c) a plateau of oxygen uptake (less than $150 \mathrm{ml} / \mathrm{min}$ increase in $\mathrm{VO}_{2}$ during the last $60 \mathrm{~s}$ of the test). In EL subjects, the workload was increased every 2 min until $85 \%$ of the age-predicted $\mathrm{HR}_{\max }$ was achieved and $\mathrm{VO}_{2}$ max was estimated submaximally with Aino FitWare Pro - physical performance testing software (Aino Health Management, Finland). $\mathrm{VO}_{2}$ max determined at the baseline was used in all subject groups to set the workloads for cycling tests performed during the experimental design. 


\section{Experimental design}

After the baseline testing, each age and gender group was randomly divided into two subgroups for the experimental design. The subjects went through a cross-over study design during which they were randomly assigned to follow either a diet with low acid load (LD) or high acid load (HD) for 7 days. Two to four weeks after finishing the first diet period, the subjects were assigned to the alternate diet. Thus, in both diet groups the total number of subjects was 88 and the subjects acted as their own controls. For the female subjects the diet periods were scheduled in the same phase of their menstrual cycles.

Before both experimental diet periods the subjects followed their normal diet (ND) and kept a food diary for 3 days. During the last 12 hours of ND period, subjects had a 12-hour overnight fast and on the $4^{\text {th }}$ morning, fasting blood samples (PRE) were drawn from a fingertip capillary and an antecubital vein in a laboratory. The last meal before PRE samples was consistent with the normal diet of the subjects. Starting from the PRE sample, the subjects followed either LD or HD and kept food diaries for 7 days. On the $8^{\text {th }}$ morning, after a 12-hour overnight fast, fasting blood samples (POST) were drawn at the same time as the PRE sample. The last meal before the POST sample was consistent with the diet followed during the 7-day period (either LD or HD). A light breakfast, which was consistent with the assigned diet, was eaten thereafter. After 45 min of rest, resting blood samples were drawn once more (REST) before completing a cycle ergometer test (Test 2 and 3). Test 2 and 3 started with a 5-min warm-up followed by a 4-min break. Thereafter, the subjects completed three 10 min trials at 35, 55 and $75 \%$ of the $\mathrm{VO}_{2} \max$. 
The AD and YA groups also completed a trial until volitional exhaustion at a workload equivalent to $100 \%$ of $\mathrm{VO}_{2} \max$. The maximal workload was continued until volitional exhaustion occurred or a subject was unable to continue pedaling over $60 \mathrm{rpm}$. The workloads for Test 2 and 3 were determined individually by calculating each subject's $\mathrm{VO}_{2}$ at 35, 55, 75 and $100 \%$ of $\mathrm{VO}_{2}$ max obtained during Test 1 and choosing the workload corresponding to each $\mathrm{VO}_{2}$. The workloads were identical in Test 2 and 3. All workloads were separated by 4-min rest periods, during which blood samples (CT35, CT55, CT75, CT100, respectively; CT= cycling test) were collected from a fingertip capillary.

The subjects were allowed to exercise moderately during the diet periods. During the last 24 hours before every fasting blood sample the subjects were instructed to minimize their physical activity. The subjects were asked to report their physical activity along with the food diaries.

\section{Diet periods and analysis}

The diets used in the present study were designed with the help of PRAL calculations to have low and high acid loads. The PRAL values were calculated as follows: PRAL (mEq/100 g) = $0.49 \times$ protein $(\mathrm{g} / 100 \mathrm{~g})+0.037 \mathrm{x}$ phosphorous $(\mathrm{mg} / 100 \mathrm{~g})-0.021 \mathrm{x}$ potassium $(\mathrm{mg} / 100 \mathrm{~g})-$

0.026 x magnesium $(\mathrm{mg} / 100 \mathrm{~g})-0.013 \mathrm{x}$ calcium $(\mathrm{mg} / 100 \mathrm{~g})$ (Remer et al. 2003). The nutrient contents of the foodstuffs were taken from the Finnish Food Composition Database (Fineli, Finnish National Institute of Health and Welfare). 
The subjects were given exact instructions how to follow the diets. Specific 1-day menus were designed for both diet periods, and every day during the diet periods subjects repeated the meals and snacks according to the menus. The subjects noted down the amount of foods eaten in grams after weighing each foodstuff. LD was based on a large intake of vegetables and fruits and a limited use of grain and dairy products. The subjects were instructed not to eat red meat, eggs or cheese during the 7 days. However, the diet included chicken $(2 \mathrm{~g} / \mathrm{kg} / \mathrm{d})$ to ensure the adequate intake of protein. HD was planned to include no vegetables and fruits at all. It mainly consisted of grain products, chicken, red meat and eggs. Vitamin and mineral supplements were not allowed during the study periods. Within the given instructions, the subjects were advised to eat according to their perceived energy needs during the first diet period. Thus, they were allowed to adjust the amounts of foods in the menus according to their appetite without leaving anything out or adding anything. The dietary instructions for the second diet period were adjusted so that the diet periods were isoenergetic. Between the two diet periods, the subjects were advised to eat according to their habitual diet. During both experimental diet periods, the subjects were compensated with some chicken, grain products, tomato, cucumber, lettuce and mushrooms, which were received from the companies who partially funded this study. The breakfasts before the cycling tests were standard and isoenergetic in all groups with subtle adjustments in the amount of the foods. During LD, the breakfast contained approximately $370 \mathrm{kcal}$ of energy, $63 \mathrm{~g}$ of carbohydrates, $16 \mathrm{~g}$ of protein, $7.2 \mathrm{~g}$ of fat and its PRAL was $-12.4 \mathrm{mEq}$. During HD, the breakfast contained $370 \mathrm{kcal}$ of energy, $33 \mathrm{~g}$ of carbohydrates, $21 \mathrm{~g}$ of protein, $16 \mathrm{~g}$ of fat and its PRAL was $7.4 \mathrm{mEq}$. 
The food diaries were analyzed for energy, protein, carbohydrate, fat, phosphorous, potassium, magnesium and calcium intake using Nutri-Flow software (Flow-Team Oy, Oulu, Finland). The average daily PRAL during LD and HD were calculated according to the relevant dietary intake data.

\section{Blood sampling and analysis}

All capillary and antecubital vein blood samples were drawn at the same time in the morning during both diet periods. Li-heparinized whole blood samples (200 and $20 \mu \mathrm{l})$ from a fingertip capillary were analyzed immediately after sampling for $\mathrm{pH}, \mathrm{HCO}_{3}{ }^{-}$, standard $\mathrm{BE}$ and lactate. The determination of $\mathrm{pH}$ was based on the principle of ion selective electrode whereas $\mathrm{HCO}_{3}{ }^{-}$and $\mathrm{BE}$ were determined computationally from $\mathrm{pH}$ and $\mathrm{pCO}_{2}$ values (GEM Premier 3000, Instrumentation Laboratory, Lexington, MA, USA). Lactate was analyzed by the amperometric and enzymatic method (BIOSEN C_line, Sport, EKF Diagnostic, Magdeburg, Germany). The blood samples from antecubital vein were drawn in vacuum tubes and centrifuged for $10 \mathrm{~min}$ at $3500 \mathrm{rpm}$. The serum was separated and creatinine was analyzed by KoneLab 20 XTi analyzator (Thermo Electron Corporation, Vantaa, Finland). Serum creatinine values were used to calculate the glomerular filtration rate (GFR) with the CKD-EPI equation, which uses also age, race, gender and body size to estimate GFR (Levey et al. 2009).

\section{Breath gas analysis}


In all three cycle ergometer tests, the gaseous exchange was measured using Jaeger Oxycon Pro breath-by-breath gas analyzer (VIASYS Healthcare GmbH, Hoechburg, Germany). The device was calibrated for volume and gas analyzer before every measurement. Cardiorespiratory variables $\left(\mathrm{VO}_{2}, \mathrm{RER}\right)$ were determined as a mean from the final 30 seconds of every workload.

\section{Statistical analysis}

Differences in blood variables between the diet groups were tested with mixed models with random ID. Comparisons were made separately at rest (PRE and POST) and during the cycling test day (POST, REST, CT35, CT55, CT75 and CT100). When the main effect of diet composition, age, gender or time (between PRE and POST) was statistically significant the comparison was continued with LSD pairwise comparisons. The effect of dietary acid load on cardiorespiratory variables and GFR was examined by two-way repeated measures analysis of variance (ANOVA), and if a statistically significant difference was observed, the comparison was continued by a paired t-test. The variables of dietary intake analysis and the difference in the duration of maximal workload were compared inside each age and gender group with paired samples t-test. The correlations of GFR with acid-base parameters were analyzed by Pearson correlation analysis. Statistical analyses were performed with IBM SPSS Statistics 22.0 (SPSS, Inc., an IBM Company). Data are presented as means \pm SDs. The statistical difference was significant at the $\mathrm{P}<0.05$ level.

\section{Results}


Altogether 88 subjects of 93 completed the study design and followed both LD and HD for 7 days in a randomized order. One subject of every age and gender group except EL men dropped out before the second diet period. Those subjects were excluded from the statistical analysis.

\section{Dietary intake}

The PRAL and macronutrient contents were not different between the ND periods that preceded both LD and HD in any of the subject groups. The PRAL values presented in Table 1 are means from these two 3-day normal diet periods.

Experimental dietary intake data are presented in Table 2. PRAL was significantly lower $(\mathrm{P}<0.001$ in all groups) and intake of vegetables and fruits was significantly higher $(\mathrm{P} \leq 0.001)$ in LD compared to HD in all groups. In AD boys and EL women the energy intake did not differ between the diets, but in other groups it was significantly lower during LD compared to HD $(\mathrm{P} \leq 0.022)$. The protein intake $(\mathrm{g} / \mathrm{kg} / \mathrm{d})$ was significantly lower $(\mathrm{P}<0.001)$ during $\mathrm{LD}$ compared to HD in all groups except in AD girls.

\section{Glomerular filtration rate}

The GFR data are presented in Figure 1. In young men, GFR decreased over the LD period $(\mathrm{P}=0.009)$ and in the elderly men and women it was higher after $\mathrm{HD}$ compared to $\mathrm{LD}(\mathrm{P}<0.001$ and $\mathrm{P}=0.047$, respectively). Age had a significant $(\mathrm{P}<0.001)$ effect on GFR. GFR was significantly lower $(\mathrm{P}<0.001)$ in young adults compared to the adolescents, in the elderly 
compared to young adults and in the elderly compared to adolescents throughout the study period. Gender also had a significant $(\mathrm{P}<0.001)$ effect on GFR. GFR was higher $(\mathrm{P} \leq 0.009)$ in boys compared to girls at all points. GFR was also higher $(\mathrm{P} \leq 0.030)$ in YA men compared to YA women at all points except at POST after LD. In the elderly, the gender differences in GFR were smaller and it was significantly higher $(\mathrm{P}=0.029)$ in men compared to women only at $\mathrm{PRE}$ during HD.

In all male subjects together, GFR correlated negatively with $\mathrm{HCO}_{3}^{-}(\mathrm{r}=-0.42, \mathrm{P}=0.007)$ and $\mathrm{BE}$ $(\mathrm{r}=-0.43, \mathrm{P}=0.006)$ at rest at the beginning of the HD period. After HD, GFR correlated with $\mathrm{HCO}_{3}{ }^{-}(\mathrm{r}=0.57, \mathrm{P}=0.003)$ and $\mathrm{BE}(\mathrm{r}=0.60, \mathrm{P}=0.001)$ at $\mathrm{CT} 100$. Moreover, GFR correlated with $\mathrm{BE}$ at $\mathrm{CT} 35$ and $\mathrm{CT} 55(\mathrm{r}=0.32, \mathrm{P}=0.039 ; \mathrm{r}=0.31, \mathrm{P}=0.045$, respectively). In all female subjects together, GFR correlated with $\mathrm{HCO}_{3}{ }^{-}$and $\mathrm{BE}$ at $\mathrm{CT} 100$ after both diet periods (LD: $\mathrm{r}=0.57$, $\mathrm{P}=0.003 ; \mathrm{r}=0.57, \mathrm{P}=0.004$, respectively. $\mathrm{HD}: \mathrm{r}=0.53, \mathrm{P}=0.013 ; \mathrm{r}=0.58, \mathrm{P}=0.006$, respectively).

\section{Blood acid-base status and lactate}

For $\mathrm{HCO}_{3}{ }^{-}$and $\mathrm{BE}$, the time $\mathrm{x}$ age effects were significant $(\mathrm{P}<0.001)$ at rest and in exercise. During exercise, diet $\mathrm{x}$ age and time $\mathrm{x}$ gender effects were significant for $\mathrm{HCO}_{3}{ }^{-}(\mathrm{P}=0.026$ and $\mathrm{P}=0.005$, respectively) and $\mathrm{BE}(\mathrm{P}=0.028$ and $\mathrm{P}=0.002$, respectively). For $\mathrm{pH}$, the time $\mathrm{x}$ age $(\mathrm{P}<0.001)$ and time $\mathrm{x}$ gender $(\mathrm{P}=0.002)$ effects were significant during exercise. In general, the changes in $\mathrm{HCO}_{3}{ }^{-}$and $\mathrm{BE}$ between the diet periods were larger in the elderly compared to younger subject groups at rest and during exercise. During exercise, the decrease in acid-base parameters within each of the diet periods was larger in young adults compared to adolescents 
and the elderly and in men compared to women. In addition, in lactate, time $\mathrm{x}$ age and time $\mathrm{x}$ gender effects were significant $(\mathrm{P}<0.001)$ during exercise.

Elderly women. Capillary $\mathrm{pH}, \mathrm{HCO}_{3}{ }^{-}$and $\mathrm{BE}$ decreased $(\mathrm{P}<0.001)$ over the $\mathrm{HD}$ period and were higher $(\mathrm{P}<0.001)$ at POST after LD compared to HD (Figure 2, Figure 3, Figure 4, respectively). $\mathrm{BE}$ increased $(\mathrm{P}=0.048)$ during $\mathrm{LD}$. Lactate was higher before the cycling test at REST after LD compared to $\mathrm{HD}(3.0 \pm 0.5$ vs. $2.0 \pm 0.5 \mathrm{mmol} / \mathrm{l}, \mathrm{P}=0.026)$ (Figure 5). After LD compared to HD, both $\mathrm{HCO}_{3}{ }^{-}(\mathrm{P} \leq 0.020)$ and $\mathrm{BE}(\mathrm{P} \leq 0.011)$ sustained at significantly higher level throughout the cycling test. Moreover, $\mathrm{pH}$ was higher also at CT75 (P=0.002) after LD compared to HD.

Elderly men. $\mathrm{HCO}_{3}{ }^{-}$and $\mathrm{BE}$ decreased significantly $(\mathrm{P}<0.001)$ over the $\mathrm{HD}$ period. $\mathrm{HCO}_{3}{ }^{-}$ increased $(\mathrm{P}=0.039)$ during the $\mathrm{LD}$ diet. After $\mathrm{LD}$ compared to $\mathrm{HD}, \mathrm{pH}(\mathrm{P}=0.021) \mathrm{HCO}_{3}{ }^{-}$ $(\mathrm{P}<0.001)$ and $\mathrm{BE}(\mathrm{P}<0.001)$ were higher at POST. BE was higher also at CT75 $(\mathrm{P}=0.021)$ after LD compared to HD. There were no differences in lactate concentrations between the diet periods at rest or during exercise.

Young women. Capillary $\mathrm{pH}(\mathrm{P}=0.019), \mathrm{HCO}_{3}{ }^{-}(\mathrm{P}=0.001)$ and $\mathrm{BE}(\mathrm{P}<0.001)$ decreased over the HD period. During LD compared to $\mathrm{HD}, \mathrm{BE}(\mathrm{P}=0.039)$ was higher at $\mathrm{PRE}$ and $\mathrm{pH}, \mathrm{HCO}_{3}{ }^{-}$and BE were higher at POST $(\mathrm{P}<0.001)$. Moreover, $\mathrm{HCO}_{3}{ }^{-}(\mathrm{P} \leq 0.022)$ and $\mathrm{BE}(\mathrm{P} \leq 0.015)$ were higher at all submaximal stages and $\mathrm{pH}$ at $\mathrm{CT} 75(\mathrm{P}=0.005)$. Also, lactate was higher at CT100 after LD compared to $\mathrm{HD}(10.0 \pm 1.8$ vs. $8.6 \pm 1.2 \mathrm{mmol} / \mathrm{l}, \mathrm{P}=0.002)$. 
Young men. Capillary $\mathrm{pH}(\mathrm{P}=0.039), \mathrm{HCO}_{3}{ }^{-}(\mathrm{P}=0.027)$ and $\mathrm{BE}(\mathrm{P}=0.012)$ decreased over the HD period. After LD compared to $\mathrm{HD}, \mathrm{pH}(\mathrm{P}=0.038), \mathrm{HCO}_{3}{ }^{-}(\mathrm{P}=0.042)$ and $\mathrm{BE}(\mathrm{P}=0.011)$ were higher at POST. Moreover, $\mathrm{pH}$ was higher at CT100 $(\mathrm{P}=0.034)$. There were no significant differences in lactate between the diet periods.

Adolescents. In the group of AD the only diet-induced change in the blood variables was the significant increase of $\mathrm{HCO}_{3}{ }^{-}(\mathrm{P}=0.005)$ and $\mathrm{BE}(\mathrm{P}=0.003)$ during the $\mathrm{LD}$ diet period in girls.

\section{Exercise performance and cardiorespiratory responses}

The elderly. Four older women were not able to finish the CT75 after the HD period. One older man was not able to finish the CT75 after either LD or HD. The duration of CT75 was shorter after HD compared to LD both in men $(9.66 \pm 1.39$ vs. $9.81 \pm 0.79 \mathrm{~min})$ and women $(9.23 \pm 2.07$ vs. $10.0 \pm 0 \mathrm{~min})$ but the differences were not significant. In men, RER was lower $(\mathrm{P} \leq 0.009)$ at all submaximal workloads after HD compared to LD (Table 3). In women, there were no differences in cardiorespiratory responses between the diet periods.

Young adults. In women the duration of the maximal workload was shorter after HD compared to $\mathrm{LD}(3.12 \pm 1.01$ vs. $3.84 \pm 1.28 \mathrm{~min}, \mathrm{P}=0.001) . \mathrm{VO}_{2}(\mathrm{P}=0.006), \mathrm{RER}(\mathrm{P}=0.029)$ and $\mathrm{HR}$ $(\mathrm{P}=0.004)$ were lower at $\mathrm{CT} 100$ after HD compared to LD. RER $(\mathrm{P}=0.023)$ and HR $(\mathrm{P}=0.026)$ were lower also at CT35 after HD compared to LD. In men there were no differences in the duration of maximal workload $(3.79 \pm 1.48$ vs. $3.67 \pm 1.20 \mathrm{~min}$, respectively) or in cardiorespiratory responses between HD and LD. 
Adolescents. There were no significant differences in exercise performance or cardiorespiratory measures between the diet groups of adolescents. In boys, the time until exhaustion at CT100 was $3.21 \pm 1.74 \mathrm{~min}$ after LD and $3.34 \pm 1.58 \mathrm{~min}$ after HD. In girls, the durations were $3.20 \pm$ $0.78 \mathrm{~min}$ and $3.17 \pm 0.88 \mathrm{~min}$, respectively.

There was no period effect in cardiorespiratory measures between the experimental diet periods. Highest $\mathrm{VO}_{2}$ obtained during the cycling test and the duration of the last workload were not different between the first and second experimental diet period regardless of the sequence of the diets followed.

\section{Discussion}

During the present study adolescents, young adults and the elderly followed one diet with low (LD) and one with high acid load (HD) for seven days to examine the effects associated with diet composition on blood acid-base status and exercise performance. To the best of our knowledge, our study is the first to suggest that better renal function may be associated with higher base availability, which can diminish exercise-induced acidosis. This could be particularly important for the elderly who have diminished renal function. Our results show that in healthy, recreationally active men and women, $\mathrm{pH}, \mathrm{HCO}_{3}{ }^{-}$and $\mathrm{BE}$ were lower after a 7-day $\mathrm{HD}$ compared to a 7-day LD, which is an indication of more acidic blood acid-base status. Particularly in young and elderly women, the blood was more acidic also during submaximal cycling. These changes affected the performance in young women, as their maximal 
cardiorespiratory measures were lower and the time of exhaustion shorter after HD compared to LD. Our data is in accordance with the literature as we found a clear decrease in GFR with aging. This likely explains why the diet-induced changes in blood acid-base status were greater in elderly subjects compared to younger groups. Moreover, women had lower GFR compared to men and consequently were more sensitive to changes in dietary acid load.

It has been suggested that the acidity of the body increases with aging as the functional capacity of the kidneys declines (Frassetto and Sebastian 1996, Goraya et al. 2012). Our cross-sectional data does not allow us making a conclusion how acid-base status of a certain individual has changed from adulthood to elderly, but in our data, despite the clear decline in GFR with aging, the acidity of the blood was not higher in the elderly compared to younger subjects. This might be affected by the fact that the elderly subjects had lower dietary acid intake during their habitual diets compared to younger subjects. Moreover, Wesson and Simoni (2009) comparing rats with and without subtotal nephrectomy, demonstrated no differences in blood acid-base levels between the two groups. However, the rats with lower kidney mass were not able to excrete the same acid load in the urine, while at the same time demonstrated higher renal tissue acid levels. We suggest a similar effect might be occurring in the relatively reduced functional renal tissue in the elderly subjects. According to the analyzed daily PRAL, the experimental diets used in the present study had low and high dietary acid loads. A high intake of vegetables and fruits and a low intake of meat, grains, eggs and cheese during LD and the opposite dietary pattern during HD caused the difference in dietary acid loads. Diets that have low acid load and promote alkalinity of the body may be beneficial for the health of elderly populations, who have decreased renal functional capacity to excrete acids. Reducing dietary acid load with increased 
intake of vegetables and fruits or bicarbonate supplementation has been reported to decrease the risk factors for chronic kidney disease (Banerjee et al. 2014, de Brito-Ashurst et al. 2009). These diets may also help in the preservation of muscle mass (Dawson-Hughes et al. 2008, Welch et al. 2013), and lower serum bicarbonate has been reported to associate with reduced muscle strength, and greater risk of incident and functional limitations (Abramowitz et al. 2011, Yencheck et al. 2014). It is important to acknowledge the significance of adequate protein intake for health (Westerterp-Plantenga et al. 2012) and in maintaining or improving skeletal muscle size (Houston et al. 2008, Hulmi et al. 2009). Our results show that to reduce the body's acid load the dietary protein intake does not have to be low; instead, it can be sustained at a moderately higher level than the current recommended daily allowance $(0.8 \mathrm{~g} / \mathrm{kg} / \mathrm{d})$ if the intake of fruits and vegetables is high enough.

Similar to the elderly subjects, in young men and women, $\mathrm{pH}, \mathrm{HCO}_{3}{ }^{-}$and $\mathrm{BE}$ decreased significantly over the HD period. In contrast, the only significant change in acid-base status of adolescents occurred in girls, as $\mathrm{HCO}_{3}{ }^{-}$and $\mathrm{BE}$ increased during the period of LD. The difference in the acid loads between the experimental diet periods was smaller in adolescents compared to the older subjects, which may have impacted the acid-base responses in adolescents. However, adolescents' acid-base status may not be as sensitive to altered diet composition as is the acid-base status of adults and the elderly, since their renal functional capacity is also higher compared with older subjects. Moreover, adolescents have higher oxidative capacity compared with adults at rest (Ratel et al. 2006), which could enable a more efficient utilization of $\mathrm{H}^{+}$in tricarboxylic acid cycle. Growing adolescents also have higher needs for protein to ensure the growing and maturation of the tissues and the efficacy to use nitrogen is increased (Giovannini et 
al. 2000). Thus, at least the acute potential of proteins to increase the acid load of the body might be lower in adolescents.

To the best of our knowledge, the effects of dietary acid load have not been reported during exercise in the elderly. In elderly women, $\mathrm{HCO}_{3}{ }^{-}$and $\mathrm{pH}$ were significantly lower during submaximal cycling after HD compared to LD. In addition, $\mathrm{pH}$ was significantly lower at $75 \%$ of $\mathrm{VO}_{2} \mathrm{max}$ after $\mathrm{HD}$ compared to LD in elderly men. Dietary acid load could be an important issue for the health of the elderly also in relation to exercise, as exercise-induced increase in acidosis was smaller after lower dietary acid load. This would diminish the need of aging kidneys to secrete acids. It could also be hypothesized that the more alkaline body prior to exercise would favor greater lipid oxidation (Sahlin and Harris 2008). That did not get support from our results as respiratory exchange ratio (RER; $\mathrm{CO}_{2}$ production $/ \mathrm{O}_{2}$ uptake) of elderly men was significantly higher at all submaximal workloads after LD compared to HD. However, the higher carbohydrate intake during LD compared to HD has likely affected the RER values. Yet there were no differences in elderly women's cardiorespiratory measures between the diet periods.

In YA women, the time to exhaustion at a workload equivalent to $100 \%$ of $\mathrm{VO}_{2}$ max was $19 \%$ shorter and their maximal $\mathrm{VO}_{2}, \mathrm{RER}$ and $\mathrm{HR}$ were lower after HD compared to LD. The maximal aerobic capacity of young men was not different between the diets. Interestingly, young women in this study depleted blood $\mathrm{HCO}_{3}{ }^{-}$during the maximal workload to the same level after both diet periods even though it was significantly higher at submaximal workloads after LD compared to $\mathrm{HD}$. In addition, $\mathrm{BE}$ and $\mathrm{pH}$ decreased to the same level after both diets. These 
results are in accordance with the results of Greenhaff et al. (1987), who reported that $\mathrm{pH}, \mathrm{HCO}_{3}{ }^{-}$ and BE were higher at rest but decreased to the same or even lower level while the cycling time to exhaustion at $100 \%$ of $\mathrm{VO}_{2} \max$ was longer after a low compared to a high dietary acid intake. Our results support the idea that consuming an LD diet produces a more alkaline environment within the body and results in a greater blood buffering capacity. This may play an important role in delaying the fatigue during submaximal and maximal exercise intensities particularly in women, who have lower renal functional capacity compared to men. Moreover, young men and women had significantly lower $\mathrm{pH}, \mathrm{HCO}_{3}{ }^{-}$and $\mathrm{BE}$ compared to both elderly men and women and boys and girls at two highest exercise intensities after adjusting for $\mathrm{VO}_{2} \mathrm{max}$. This and the positive correlations between GFR and acid-base parameters suggest that the renal functional capacity may affect the level of acidity that is possible to achieve during high-intensity exercise in young and elderly adults. The performance or exercise metabolism of adolescents, however, was not different between the diet groups. It is important to recognize that not only ergogenic aids but also a habitual diet may have a constant effect on bicarbonate concentrations of the body. According to this study, particularly women should pay attention to adequate consumption of vegetables and fruits to maximize their performance during high-intensity exercise.

Young women had higher maximal blood lactate after LD compared to HD. This is in accordance with a hypothesis that increased pre-exercise alkalosis might enhance high-intensity performance by contributing to enhanced glycolytic ATP production (Stephens et al. 2002). For example, in the study of Hollidge-Horvat et al. (2000), sodium bicarbonate -induced alkalosis increased muscle glycogen use, lactate accumulation and production, and muscle $\mathrm{H}^{+}$ concentration. Similarly, in the study of Oöpik et al. (2003), subjects had $21 \%$ higher maximal 
blood lactate and completed a 5-km time trial $2.6 \%$ faster after a citrate supplementation compared to placebo. Moreover, RER of the young women was at higher level during cycling after $\mathrm{LD}$ compared to $\mathrm{HD}$ with a significant difference at $35 \%$ and $100 \%$ of $\mathrm{VO}_{2}$ max indicating that carbohydrate oxidation was increased after low dietary acid load. In contrast, in a study of Caciano et al. (2015), submaximal and maximal RER were lower after a 7-day low-PRAL diet and there were only trends towards a longer time to exhaustion and greater maximal $\mathrm{VO}_{2}$ during a graded treadmill exercise test. The blood acid-base parameters were not measured during that study. In our study, the difference in carbohydrate intakes between the diet groups is one of the limitations of this study, and lower carbohydrate intake may have influenced the RER values_and exercise capacity during HD. However, we think the difference in the intake of carbohydrates was not large enough to solely explain the difference in time to exhaustion by lower muscle glycogen availability. In the group of young women, the cycling tests performed during the study lasted approximately 33 minutes. Of that, 20 minutes were cycled at 35 and $55 \%$ of $\mathrm{VO}_{2}$ max, when fat is the most dominant source of energy (Knuiman et al. 2015). Subjects were not engaging in high-intensity exercise during the study periods. Moreover, according to the body composition analysis, the weight of body fluids was not reduced over the HD period, which strengthens the postulation that the muscle glycogen stores were not depleted prior the cycling tests during the HD period.

To conclude, a diet deficient in vegetables and fruits and rich in meat and grains, leads to a high dietary acid load and may induce a more acidic blood acid-base status - that is, lower $\mathrm{pH}$, lower bicarbonate and lower base excess. The effects of dietary acid load are larger in the elderly compared to younger persons and in women compared to men, which is likely explained by the 
differences in GFR. Maintaining better renal function with aging may be associated with higher availability of bases, which also may diminish exercise-induced acidosis and decrease the need of aging kidneys to excrete acids. Decreased alkalinity of the blood may also impair maximal aerobic performance, such as occurred in the young women in this study. We conclude that the diet composition along with renal functional capacity affects acid-base status of the body at rest and in exercise. The significance of the dietary acid load as a part of a healthy diet needs to be studied further.

\section{Acknowledgements}

The authors would like to thank the participants of this study, and Tanja Laine, Johanna Ihalainen, Elina Vaara, Hanna Minkkinen, Susanna Karvinen, Riikka Lamminen and Juha Hulmi for all the assistance in establishing this study.

\section{Conflict of interest and source of funding}

This study was funded by TEKES (Finnish Funding Agency for Technology and Innovation) and in collaboration with TEKES by following Finnish companies: Honkatarhat Ltd, Honkajoki; Kyröntarhat Ltd, Honkajoki; Mykora Ltd, Honkajoki; Lihajaloste Korpela Ltd, Huittinen; Laihian Mallas Ltd, Laihia; KKK-Vihannes Ltd / LykoBEne, Honkajoki. 
Hannu Pitkänen has a commercial association with Honkatarhat LTd, Kyröntarhat Ltd and Mykora Ltd. He accepts full responsibility for the implementation of this study. Other authors declare that they have no conflict of interest.

\section{References}

Abramowitz, M.K., Hostetter, T.H., and Melamed, M.L. 2011. Association of serum bicarbonate levels with gait speed and quadriceps strength in older adults. Am. J. Kidney Dis. 58(1): 29-38. doi: 10.1053/j.ajkd.2010.12.021.

Adeva, M.M., and Souto, G. 2011. Diet-induced metabolic acidosis. Clin. Nutr. 30(4): 416-421. doi: 10.1016/j.clnu.2011.03.008.

Applegate, C., Mueller, M., and Zuniga, K.E. 2017. Influence of dietary acid load on exercise performance. Int. J. Sport Nutr. Exerc. Metab. 27(3): 213-219. doi: 10.1123/ijsnem.2016-0186.

Baguet, A., Everaert, I., De Naeyer, H., Reyngoudt, H., Stegen, S., Beeckman, S., Achten, E., Vanhee, L., Volkaert, A., Petrovic, M., Taes, Y., and Derave, W. 2011. Effects of sprint training combined with vegetarian or mixed diet on muscle carnosine content and buffering capacity. Eur. J. Appl. Phys. 111: 2571-2580. doi: 10.1007/s00421-011-1877-4.

Banerjee, T., Crews, D.C., Wesson, D.E., Tilea, A., Saran, R., Rios Burrows, N., Williams, D.E., and Powe, N.R.; Centers for Disease Control and Prevention Chronic Kidney Disease Surveillance Team. 2014. Dietary acid load and chronic kidney disease among adults in the United States. BMC Nephrol. 15: 137. doi: 10.1186/1471-2369-15-137. 
Bolignano, D., Mattace-Raso, F., Sijbrands, E.J., and Zoccali, C. 2014. The aging kidney revisited: a systematic review. Ageing Res. Rev. 14: 65-80. doi: 10.1016/j.arr.2014.02.003.

Caciano, S.L., Inman, C.L., Gockel-Blessing, E.E., and Weiss, E.P. 2015. Effects of dietary acid load on exercise metabolism and anaerobic exercise performance. J. Sports Sci. Med. 14(2): 364371.

Dawson-Hughes, B., Harris, S.S., and Ceglia, L. 2008. Alkaline diets favor lean tissue mass in older adults. Am. J. Clin. Nutr. 87: 662-665.

De Brito-Ashurst, I., Varagunam, M., Raftery, M.J., and Yaqoob, M.M. 2009. Bicarbonate supplementation slows progression of CKD and improves nutritional status. J. Am. Soc. Nephrol. 20(9): 2075-2084. doi: 10.1681/ASN.2008111205.

Frassetto, L., and Sebastian, A. 1996. Age and systemic acid-base equilibrium: analysis of published data. J. Gerontol. A. Biol. Sci. Med. Sci. 51(1): B91-99.

Giovannini, M., Agostoni, C., Gianni, M., Bernardo, L., and Riva, E. 2000. Adolescence: macronutrient needs. Eur. J. Clin. Nutr. 54(Suppl1): S7-10.

Goraya, N., Simoni, J., Jo, C., and Wesson, D.E. 2012. Dietary acid reduction with fruits and vegetables or bicarbonate attenuates kidney injury in patients with a moderately reduced glomerular filtration rate due to hypertensive nephropathy. Kidney Int. 81(1): 86-93. doi: 10.1038/ki.2011.313. 
Greenhaff, P.L., Gleeson, M., \& Maughan, R.J. 1987. The effects of dietary manipulation on blood acid-base status and the performance of high intensity exercise. Eur. J. Appl. Physiol. 56: $331-337$.

Hollidge-Horvat, M.G., Parolin, M.L., Wong, D., Jones, N.L., and Heigenhauser, G.J.F. 2000. Effect of induced metabolic alkalosis on human skeletal muscle metabolism during exercise. Am J. Physiol. Endocrinol. Metab. 278: E316-329.

Houston, D.K., Nicklas, B.J., Ding, J., Harris, T.B., Tylavsky, F.A., Newman, A.B., Lee, J.S., Sahyoun, N.R., Visser, M., and Kritchevsky, S.B.; Health ABC Study. 2008. Dietary protein intake is associated with lean mass change in older, community-dwelling adults: the Health, Aging, and Body Composition (Health ABC) Study. Am. J. Clin. Nutr. 87(1): 150-155.

Hulmi, J.J., Kovanen, V., Selänne, H., Kraemer, W.J., Häkkinen, K., and Mero, A.A. 2009. Acute and long-term effects of resistance exercise with or without protein ingestion on muscle hypertrophy and gene expression. Amino Acids. 37(2): 297-308. doi: 10.1007/s00726-0080150-6.

Knuiman, P., Hopman, M.T.E., and Mensink, M. 2015. Glycogen availability and skeletal muscle adaptations with endurance and resistance exercise. Nutr. Met. 12: 59. doi: $10.1186 / \mathrm{s} 12986-015-0055-9$

Krustrup, P., Ermidis, G., and Mohr, M. 2015. Sodium bicarbonate intake improves highintensity intermittent exercise performance in trained young men. J. Int. Soc. Sports Nutr. 12: 25. doi: 10.1186/s12970-015-0087-6. 
Lancha Junior, A.H., de Salles Painelli, V., Saunders, B., and Artioli, G.G. 2015. Nutritional strategies to modulate intracellular and extracellular buffering capacity during high-intensity exercise. Sports Medicine. 45: 71-81. doi:10.1007/s40279-015-0397-5.

Levey, A.S., Stevens, L.A., Schmid, C.H., Zhang, Y., Castro, A.F. III, Feldman, H.I., Kusek, J.W., Eggers, P., Van Lente, F., Greene, T., and Coresh, J; for the Chronic Kidney Disease Epidemiology Collaboration (CKD-EPI). A new equation to estimate glomerular filtration rate. Ann. Intern. Med. 150(9): 604-612, 2009.

Mero, A., Hirvonen, P., Saarela, J., Hulmi, J., Hoffman, J., and Stout, J. 2013. Effect of sodium bicarbonate and beta-alanine supplementation on maximal sprint swimming. J. Int. Soc. Sports Nutr. 10(1): 52. doi:10.1186/1550-2783-10-52.

Oöpik, V., Saaremets, I., Medijainen, L., Karelson, K., Janson, T., and Timpmann, S. 2003. Effects of sodium citrate ingestion before exercise on endurance performance in well trained college runners. Br. J. Sports Med. 37(6): 485-489. doi:10.1136/bjsm.37.6.485.

Poupin, N., Calvez, J. F., Lassale, C. F., Chesneau, C. F., and Tome, D. 2012. Impact of the diet on net endogenous acid production and acid-base balance. Clin. Nutr. 31(3): 313-21. doi:10.1016/j.clnu.2012.01.006.

Ratel, S., Duché, P., and Williams, C.A. 2006. Muscle fatigue during high-intensity exercise in children. Sports. Med. 36(12): 1031-1065.

Remer, T., Dimitriou, T., and Manz, F. 2003. Dietary potential renal acid load and renal net acid excretion in healthy, free-living children and adolescents. Am. J. Clin. Nutr. 77: 1255-1260. 
Robergs, R.A., Ghiasvand, F.F., \& Parker, D. 2004. Biochemistry of exercise-induced metabolic acidosis. Am. J. Physiol. Regul. Integr. Comp. Physiol. 287:R502-516. doi:10.1152/ajpregu.00114.2004.

Sahlin, K, and Harris, R.C. 2008. Control of lipid oxidation during exercise: role of energy state and mitochondrial factors. Acta Physiol. (Oxf). 194(4): 283-291. doi: 10.1111/j.17481716.2008.01879.x.

Scialla, J.J., Appel, L.J., Astor, B.C., Miller, E.R. 3rd, Beddhu, S., Woodward, M., Parekh, R.S., and Anderson CA; African American Study of Kidney Disease and Hypertension Study Group. 2012. Net endogenous acid production is associated with a faster decline in GFR in African Americans. Kidney Int. 82(1): 106-112. doi: 10.1038/ki.2012.82.

Stephens, T.J., McKenna, M.J., Canny, B.J., Snow, R.J., and McConell, G.K. 2002. Effect of sodium bicarbonate on muscle metabolism during intense endurance cycling. Med. Sci. Sports Exerc. 34(4): 614-621.

Tabatabai, L.S., Cummings, S.R., Tylavsky, F.A., Bauer, D.C., Cauley, J.A., Kritchevsky, S.B., Newman, A., Simonsick, E.M., Harris, T.B., Sebastian, A., and Sellmeyer, D.E. 2015. Arterialized venous bicarbonate is associated with lower bone mineral density and an increased rate of bone loss in older men and women. J. Clin. Endocrinol. Metab. 100(4): 1343-1349. doi: $10.1210 /$ jc. $2014-4166$.

Van Montfoort, M.C., Van Dieren, L., Hopkins, W.G., and Shearman, J.P. 2004. Effects of ingestion of bicarbonate, citrate, lactate, and chloride on sprint running. Med. Sci. Sports Exerc. 36(7): 1239-1243. 
Welch, A.A., MacGregor, A.J., Skinner, J., Spector, T.D., Moayyeri, A., and Cassidy, A. 2013. A higher alkaline dietary load is associated with greater indexes of skeletal muscle mass in women. Osteoporos. Int. 24(6): 1899-1908. doi: 10.1007/s00198-012-2203-7.

Wesson, D.E., and Simoni, J. 2009 Increased tissue acid mediates a progressive decline in the glomerular filtration rate of animals with reduced nephron mass. Kidney Int. 75(9): 929-935. doi: $10.1038 / \mathrm{ki} .2009 .6$

Westerterp-Plantenga, M.S., Lemmens, S.G., and Westerterp, K.R. 2012. Dietary protein - its role in satiety, energetics, weight loss and health. Br. J. Nutr. 108(Supp12): S105-112. doi: 10.1017/S0007114512002589.

Wilkes, D., Gledhill, N., and Smyth R. 1983. Effect of acute induced metabolic alkalosis on 800m racing time. Med. Sci. Sports Exerc. 15(4): 277-280.

Yenchek, R., Ix, J.H., Rifkin, D.E., Shlipak, M.G., Sarnak, M.J., Garcia, M., Patel, K.V., Satterfield, S., Harris, T.B., Newman, A.B., and Fried, L.F.; Health ABC Study. 2014. Association of serum bicarbonate with incident functional limitation in older adults. Clin. J. Am. Soc. Nephrol. 9(12): 2111-2116. doi: 10.2215/CJN.05480614. 
Table 1. Baseline anthropometric characteristics, PRAL of habitual diets and cardiorespiratory measures at Test 1 (mean + SD).

\begin{tabular}{lcccccc}
\hline & \multicolumn{2}{c}{ Adolescents } & \multicolumn{2}{c}{ Young adults } & \multicolumn{2}{c}{ Elderly } \\
& Boys & Girls & Men & Women & Men & Women \\
\hline N & 13 & 9 & 15 & 18 & 17 & 16 \\
Age (yr) & $13.4 \pm 1.4$ & $13.0 \pm 1.2$ & $29.1 \pm 2.7$ & $27.6 \pm 3.4$ & $67.1 \pm 3.7$ & $65.4 \pm 3.6$ \\
Weight (kg) & $52.3 \pm 10.9$ & $49.4 \pm 7.7$ & $79.5 \pm 9.7$ & $58.3 \pm 5.0$ & $78.8 \pm 10.0$ & $67.6 \pm 11.0$ \\
Height (cm) & $161 \pm 12$ & $158 \pm 6$ & $180 \pm 6$ & $165 \pm 6$ & $175 \pm 6$ & $164 \pm 7$ \\
Body fat (\%) & $13.0 \pm 7.5$ & $18.5 \pm 5.4$ & $17.3 \pm 4.6$ & $22.2 \pm 5.1$ & $22.4 \pm 6.4$ & $34.1 \pm 7.9$ \\
BMI (kg/m $)$ & $20.0 \pm 2.4$ & $19.6 \pm 2.1$ & $24.5 \pm 2.6$ & $21.6 \pm 2.2$ & $25.5 \pm 2.0$ & $25.3 \pm 3.9$ \\
PRAL (mEq/d) & $4.4 \pm 16.0$ & $-5.7 \pm 23.3$ & $1.7 \pm 17.0$ & $-13 \pm 17$ & $-4.4 \pm 9.5$ & $-14 \pm 12$ \\
VO $\mathbf{2}$ max (1/min) & $2.9 \pm 0.9$ & $2.3 \pm 0.5$ & $4.2 \pm 0.5$ & $2.7 \pm 0.5$ & $2.5 \pm 0.3$ & $1.9 \pm 0.2$ \\
RER & $0.97 \pm 0.04$ & $1.01 \pm 0.04$ & $1.05 \pm 0.06$ & $1.04 \pm 0.07$ & - & - \\
Heart rate (bpm) & $186 \pm 13$ & $190 \pm 7$ & $189 \pm 9$ & $187 \pm 8$ & $161 \pm 3$ & $162 \pm 2$
\end{tabular}


Table 2. Dietary intake data during LD and HD in all subject groups.

\begin{tabular}{|c|c|c|c|c|c|c|c|c|c|c|c|c|}
\hline & \multicolumn{4}{|c|}{ Adolescents } & \multicolumn{4}{|c|}{ Young adults } & \multicolumn{4}{|c|}{ Elderly } \\
\hline & \multicolumn{2}{|c|}{ Boys } & \multicolumn{2}{|c|}{ Girls } & \multicolumn{2}{|c|}{ Men } & \multicolumn{2}{|c|}{ Women } & \multicolumn{2}{|c|}{ Men } & \multicolumn{2}{|c|}{ Women } \\
\hline & LD & HD & LD & HD & LD & HD & LD & HD & LD & HD & LD & HD \\
\hline $\begin{array}{l}\text { PRAL } \\
(\mathrm{mEq} / \mathrm{d})\end{array}$ & $\begin{array}{l}-47 \pm \\
44 * * *\end{array}$ & $25 \pm 11$ & $\begin{array}{l}-43 \pm \\
18^{* * *}\end{array}$ & $15 \pm 16$ & $-68 \pm 30 * * *$ & $61 \pm 22$ & $-68 \pm 17 * * *$ & $47 \pm 8.3$ & $-61 \pm 17 * * *$ & $57 \pm 12$ & $-63 \pm 12 * * *$ & $49 \pm 14$ \\
\hline IVF (g/d) & $\begin{array}{l}830 \pm \\
630 * *\end{array}$ & $40 \pm 18$ & $\begin{array}{c}890 \pm \\
370 * * *\end{array}$ & $28 \pm 16$ & $\begin{array}{c}1410 \pm \\
460 * * *\end{array}$ & $24 \pm 11$ & $\begin{array}{c}1400 \pm \\
350 * * *\end{array}$ & $22 \pm 8$ & $\begin{array}{l}1270 \pm \\
380 * * *\end{array}$ & $20 \pm 8$ & $\begin{array}{l}1350 \pm \\
290 * * *\end{array}$ & $17 \pm 6$ \\
\hline $\begin{array}{l}\text { Energy } \\
\text { (kcal/d) }\end{array}$ & $\begin{array}{c}1790 \pm \\
570\end{array}$ & $\begin{array}{c}1980 \pm \\
610\end{array}$ & $\begin{array}{c}1360 \pm \\
200 *\end{array}$ & $\begin{array}{c}1610 \pm \\
300\end{array}$ & $\begin{array}{l}2090 \pm \\
600 * *\end{array}$ & $\begin{array}{c}2330 \pm \\
670\end{array}$ & $1650 \pm 230^{*}$ & $\begin{array}{c}1780 \pm \\
300\end{array}$ & $1930 \pm 350 *$ & $\begin{array}{c}2070 \pm \\
350\end{array}$ & $1690 \pm 290$ & $\begin{array}{c}1690 \pm \\
330\end{array}$ \\
\hline $\begin{array}{l}\text { Protein } \\
(\mathrm{g} / \mathrm{kg} / \mathrm{d})\end{array}$ & $\begin{array}{c}1.3 \pm \\
0.4^{* * *}\end{array}$ & $2.1 \pm 0.5$ & $1.0 \pm 0.2$ & $1.5 \pm 0.7$ & $1.3 \pm 0.4 * * *$ & $2.1 \pm 0.6$ & $1.2 \pm 0.2 * * *$ & $2.3 \pm 0.3$ & $1.1 \pm 0.2^{* * *}$ & $1.9 \pm 0.4$ & $1.0 \pm 0.2 * * *$ & $1.9 \pm 0.5$ \\
\hline Protein (\%) & $16 \pm 3.4^{* *}$ & $22 \pm 3.7$ & $\begin{array}{c}13 \pm \\
3.0 * * *\end{array}$ & $22 \pm 4.7$ & $19 \pm 3.6^{* * *}$ & $27 \pm 2.2$ & $17 \pm 2.5^{* * *}$ & $30 \pm 3.9$ & $17 \pm 1.7 * * *$ & $\begin{array}{c}29 \pm \\
2.9 * * *\end{array}$ & $16 \pm 2.8$ & $29 \pm 2.5$ \\
\hline $\begin{array}{l}\text { CHO } \\
(\mathrm{g} / \mathrm{kg} / \mathrm{d})\end{array}$ & $4.9 \pm 1.6$ & $4.5 \pm 1.8$ & $4.4 \pm 0.6$ & $3.3 \pm 1.4$ & $3.9 \pm 1.2^{* * *}$ & $3.1 \pm 1.0$ & $4.2 \pm 0.9 * * *$ & $3.2 \pm 0.7$ & $3.4 \pm 0.9 * * *$ & $2.8 \pm 0.9$ & $3.4 \pm 0.8 * * *$ & $2.7 \pm 0.8$ \\
\hline CHO (\%) & $57 \pm 5.5^{* *}$ & $46 \pm 8.1$ & $\begin{array}{c}61 \pm \\
5.4 * * *\end{array}$ & $46 \pm 5.9$ & $56 \pm 6.5^{* * *}$ & $39 \pm 3.4$ & $57 \pm 5.0 * * *$ & $41 \pm 4.3$ & $54 \pm 3.9 * * *$ & $\begin{array}{c}41 \pm \\
3.9 * * *\end{array}$ & $52 \pm 4.4^{* * *}$ & $41 \pm 4.1$ \\
\hline $\begin{array}{l}\text { Fat } \\
(\mathrm{g} / \mathrm{kg} / \mathrm{d})\end{array}$ & $\begin{array}{c}1.0 \pm \\
0.3 * * *\end{array}$ & $1.3 \pm 0.4$ & $\begin{array}{c}0.8 \pm \\
0.3 * * *\end{array}$ & $1.2 \pm 0.3$ & $0.7 \pm 0.3 * * *$ & $1.1 \pm 0.3$ & $0.7 \pm 0.2 * * *$ & $1.0 \pm 0.3$ & $0.7 \pm 0.2^{* *}$ & $0.9 \pm 0.2$ & $0.9 \pm 0.2$ & $0.8 \pm 0.2$ \\
\hline Fat $(\%)$ & $\begin{array}{c}25 \pm \\
4.2 * * *\end{array}$ & $31 \pm 4.8$ & $26 \pm 8.1$ & $32 \pm 3.1$ & $22 \pm 5.8 * * *$ & $31 \pm 4.6$ & $23 \pm 4.9 * * *$ & $28 \pm 4.6$ & $26 \pm 3.9^{* *}$ & $29 \pm 3.7$ & $29 \pm 4.4$ & $28 \pm 4.4$ \\
\hline
\end{tabular}

LD, diet with low acid load; HD diet with high acid load; PRAL, potential renal acid load; IVF, intake of vegetables and fruits; CHO, carbohydrates.

$* \mathrm{P}<0.05, * * \mathrm{P}<0.01, * * * \mathrm{P}<0.001$, statistically significant difference between LD and HD inside each subject group (Paired samples t-test). Values are mean $\pm \mathrm{SD}$. 
Table 3. Cardiorespiratory variables during the cycle ergometer tests after LD and HD in all subject groups.

\begin{tabular}{|c|c|c|c|c|c|c|c|c|c|c|c|c|c|}
\hline & \multirow{3}{*}{$\begin{array}{c}\text { Workload } \\
\left(\% \text { of } \mathrm{VO}_{2} \mathrm{max}\right)\end{array}$} & \multicolumn{6}{|c|}{ Men } & \multicolumn{6}{|c|}{ Women } \\
\hline & & \multicolumn{2}{|c|}{$\mathrm{VO}_{2}(\mathrm{l} / \mathrm{min})$} & \multicolumn{2}{|c|}{ RER } & \multicolumn{2}{|c|}{ HR } & \multicolumn{2}{|c|}{$\mathrm{VO}_{2}(\mathrm{l} / \mathrm{min})$} & \multicolumn{2}{|c|}{ RER } & \multicolumn{2}{|c|}{ HR } \\
\hline & & LD & HD & LD & HD & LD & HD & LD & HD & LD & HD & LD & HD \\
\hline \multirow[t]{4}{*}{ AD } & 35 & $1.10 \pm 0.31$ & $1.06 \pm 0.30$ & $0.83 \pm 0.04$ & $0.80 \pm 0.05$ & $116 \pm 12$ & $113 \pm 14$ & $0.90 \pm 0.17$ & $0.91 \pm 0.18$ & $0.84 \pm 0.02$ & $0.81 \pm 0.03$ & $121 \pm 9$ & $121 \pm 10$ \\
\hline & 55 & $1.70 \pm 0.50$ & $1.71 \pm 0.48$ & $0.84 \pm 0.04$ & $0.83 \pm 0.02$ & $149 \pm 13$ & $146 \pm 16$ & $1.39 \pm 0.26$ & $1.40 \pm 0.30$ & $0.86 \pm 0.03$ & $0.84 \pm 0.02$ & $149 \pm 10$ & $152 \pm 12$ \\
\hline & 75 & $2.44 \pm 0.65$ & $2.48 \pm 0.65$ & $0.88 \pm 0.05$ & $0.87 \pm 0.03$ & $179 \pm 10$ & $178 \pm 13$ & $1.94 \pm 0.39$ & $1.99 \pm 0.36$ & $0.90 \pm 0.02$ & $0.89 \pm 0.03$ & $176 \pm 8$ & $180 \pm 10$ \\
\hline & 100 & $2.97 \pm 0.97$ & $3.05 \pm 0.89$ & $0.92 \pm 0.1$ & $0.92 \pm 0.09$ & $194 \pm 9$ & $192 \pm 12$ & $2.33 \pm 0.35$ & $2.35 \pm 0.39$ & $0.97 \pm 0.05$ & $0.93 \pm 0.06$ & $187 \pm 5$ & $188 \pm 5$ \\
\hline \multirow[t]{4}{*}{$\mathbf{Y A}$} & 35 & $1.51 \pm 0.23$ & $1.53 \pm 0.19$ & $0.83 \pm 0.03$ & $0.83 \pm 0.04$ & $108 \pm 9$ & $108 \pm 11$ & $1.06 \pm 0.19$ & $1.04 \pm 0.16$ & $0.84 \pm 0.04 *$ & $0.82 \pm 0.03$ & $116 \pm 13^{*}$ & $111 \pm 12$ \\
\hline & 55 & $2.27 \pm 0.42$ & $2.35 \pm 0.29$ & $0.87 \pm 0.04$ & $0.87 \pm 0.04$ & $140 \pm 11$ & $142 \pm 14$ & $1.55 \pm 0.22$ & $1.53 \pm 0.23$ & $0.86 \pm 0.04$ & $0.85 \pm 0.03$ & $147 \pm 9$ & $143 \pm 13$ \\
\hline & 75 & $3.32 \pm 0.51$ & $3.31 \pm 0.43$ & $0.94 \pm 0.05$ & $0.92 \pm 0.04$ & $172 \pm 9$ & $171 \pm 11$ & $2.17 \pm 0.28$ & $2.11 \pm 0.31$ & $0.92 \pm 0.03$ & $0.90 \pm 0.04$ & $174 \pm 8$ & $171 \pm 9$ \\
\hline & 100 & $4.00 \pm 0.47$ & $4.05 \pm 0.43$ & $1.02 \pm 0.09$ & $1.02 \pm 0.10$ & $187 \pm 10$ & $187 \pm 9$ & $2.65 \pm 0.35^{* *}$ & $2.50 \pm 0.40$ & $1.01 \pm 0.09^{*}$ & $0.99 \pm 0.10$ & $187 \pm 9 * *$ & $184 \pm 9$ \\
\hline \multirow[t]{2}{*}{ EL } & 35 & $0.97 \pm 0.11$ & $1.00 \pm 0.12$ & $0.85 \pm 0.03^{* *}$ & $0.82 \pm 0.03$ & $87 \pm 9$ & $86 \pm 11$ & $0.81 \pm 0.09$ & $0.83 \pm 0.09$ & $0.84 \pm 0.03$ & $0.83 \pm 0.03$ & $98 \pm 13$ & $100 \pm 16$ \\
\hline & 75 & $2.02 \pm 0.28$ & $2.04 \pm 0.29$ & $0.95 \pm 0.05^{* *}$ & $0.93 \pm 0.04$ & $135 \pm 17$ & $136 \pm 16$ & $1.53 \pm 0.18$ & $1.53 \pm 0.19$ & $0.93 \pm 0.04$ & $0.92 \pm 0.05$ & $151 \pm 16$ & $152 \pm 15$ \\
\hline
\end{tabular}

After a 7-d LD and a 7-d HD, experimental cycle ergometer tests were performed, where 10 min at 35\%, 55\% and 75\% of VO ${ }_{2}$ max were cycled

(CT35, CT55, CT75). AD and YA cycled additionally at $100 \%$ of $\mathrm{VO}_{2}$ max until exhaustion (CT100). Cardiorespiratory variables were determined as a mean from the final 30 seconds of every workload. LD, diet with low acid load; HD, diet with high acid load; HR, heart rate; AD, adolescents; YA, young adults; EL, elderly. $* \mathrm{P}<0.05, * * \mathrm{P}<0.01$, statistically significant difference between LD and HD inside each subject group (two-way repeated measures analysis of variance (ANOVA), a paired samples-test). Values are mean \pm SD. 


\section{Figure Captions}

Figure 1. Glomerular filtration rate in adolescents (A), young adults (B) and the elderly (C) in the beginning (PRE) and at the end (POST) of the 7-d LD and the 7-d HD. LD, diet with low acid load; HD, diet with high acid load. $* \mathrm{P}<0.05, * * * \mathrm{P}<0.001$ statistically significant difference between LD and $\mathrm{HD} ; \uparrow \mathrm{P}<0.05$ statistically significant difference between PRE and POST during HD (mixed models with random ID, LSD pairwise comparison). Values are mean $\pm \mathrm{SD}$.

Figure 2. Capillary pH in adolescents (A), young adults (B) and elderly (C) men and women in the beginning (PRE) and at the end (POST) of the 7-d LD and the 7-d HD, after the breakfast (REST) and during exercise where $10 \mathrm{~min}$ at $35 \%, 55 \%$ and $75 \%$ of $\mathrm{VO}_{2} \max (\mathrm{CT} 35, \mathrm{CT} 55$, CT75) were cycled. Adolescents and young adults cycled additionally at $100 \%$ of $\mathrm{VO}_{2}$ max until exhaustion (CT100). LD, diet with low acid load; HD, diet with high acid load. $* \mathrm{P}<0.05, * *$ $\mathrm{P}<0.01, * * * \mathrm{P}<0.001$ statistically significant difference between $\mathrm{LD}$ and $\mathrm{HD} ; \dagger \mathrm{P}<0.05, \uparrow \dagger \dagger$ $\mathrm{P}<0.001$ statistically significant difference between PRE and POST during HD (mixed models with random ID, LSD pairwise comparison). Values are mean \pm SD.

Figure 3. Bicarbonate $\left(\mathrm{HCO}_{3}^{-}\right)$in adolescents (A), young adults (B) and elderly (C) men and women in the beginning (PRE) and at the end (POST) of the 7-d LD and the 7-d HD, after the breakfast (REST) and during exercise where $10 \mathrm{~min}$ at $35 \%, 55 \%$ and $75 \%$ of $\mathrm{VO}_{2} \max (\mathrm{CT} 35$, CT55, CT75) were cycled. Adolescents and young adults cycled additionally at $100 \%$ of $\mathrm{VO}_{2}$ max until exhaustion (CT100). LD, diet with low acid load; HD, diet with high acid load. * $\mathrm{P}<0.05, * * \mathrm{P}<0.01, * * * \mathrm{P}<0.001$, statistically significant difference between LD and HD; $\dagger$ $\mathrm{P}<0.05, \dagger \uparrow \mathrm{P}<0.01, \uparrow \dagger \uparrow \mathrm{P}<0.001$ statistically significant difference between $\mathrm{PRE}$ and POST 
during HD; \# $\mathrm{P}<0.05$, \#\# $\mathrm{P}<0.01$ statistically significant difference between $\mathrm{PRE}$ and POST during LD (mixed models with random ID, LSD pairwise comparison). Values are mean \pm SD.

Figure 4. Base excess (BE) in adolescents (A), young adults (B) and elderly (C) men and women in the beginning (PRE) and at the end (POST) of the 7-d LD and the 7-d HD, after the breakfast (REST) and during exercise where $10 \mathrm{~min}$ at $35 \%, 55 \%$ and $75 \%$ of $\mathrm{VO}_{2} \max (\mathrm{CT} 35, \mathrm{CT} 55$, CT75) were cycled. Adolescents and young adults cycled additionally at $100 \%$ of $\mathrm{VO}_{2}$ max until exhaustion (CT100). LD, diet with low acid load; HD, diet with high acid load. * $\mathrm{P}<0.05$, ** $\mathrm{P}<0.01, * * * \mathrm{P}<0.001$, statistically significant difference between $\mathrm{LD}$ and $\mathrm{HD} ; \uparrow \mathrm{P}<0.05, \uparrow \dagger \uparrow$ $\mathrm{P}<0.001$ statistically significant difference between PRE and POST during HD (mixed models with random ID, LSD pairwise comparison). Values are mean $\pm \mathrm{SD}$.

Figure 5. Lactate in adolescents (A), young adults (B) and elderly (C) men and women in the beginning (PRE) and at the end (POST) of the 7-d LD and the 7-d HD, after the breakfast (REST) and during exercise where $10 \mathrm{~min}$ at $35 \%, 55 \%$ and $75 \%$ of $\mathrm{VO}_{2} \max (\mathrm{CT} 35, \mathrm{CT} 55$, CT75) were cycled. Adolescents and young adults cycled additionally at $100 \%$ of $\mathrm{VO}_{2}$ max until exhaustion (CT100). LD, diet with low acid load; HD, diet with high acid load. $* * \mathrm{P}<0.01$, statistically significant difference between LD and HD (mixed models with random ID, LSD pairwise comparison). Values are mean $\pm \mathrm{SD}$. 

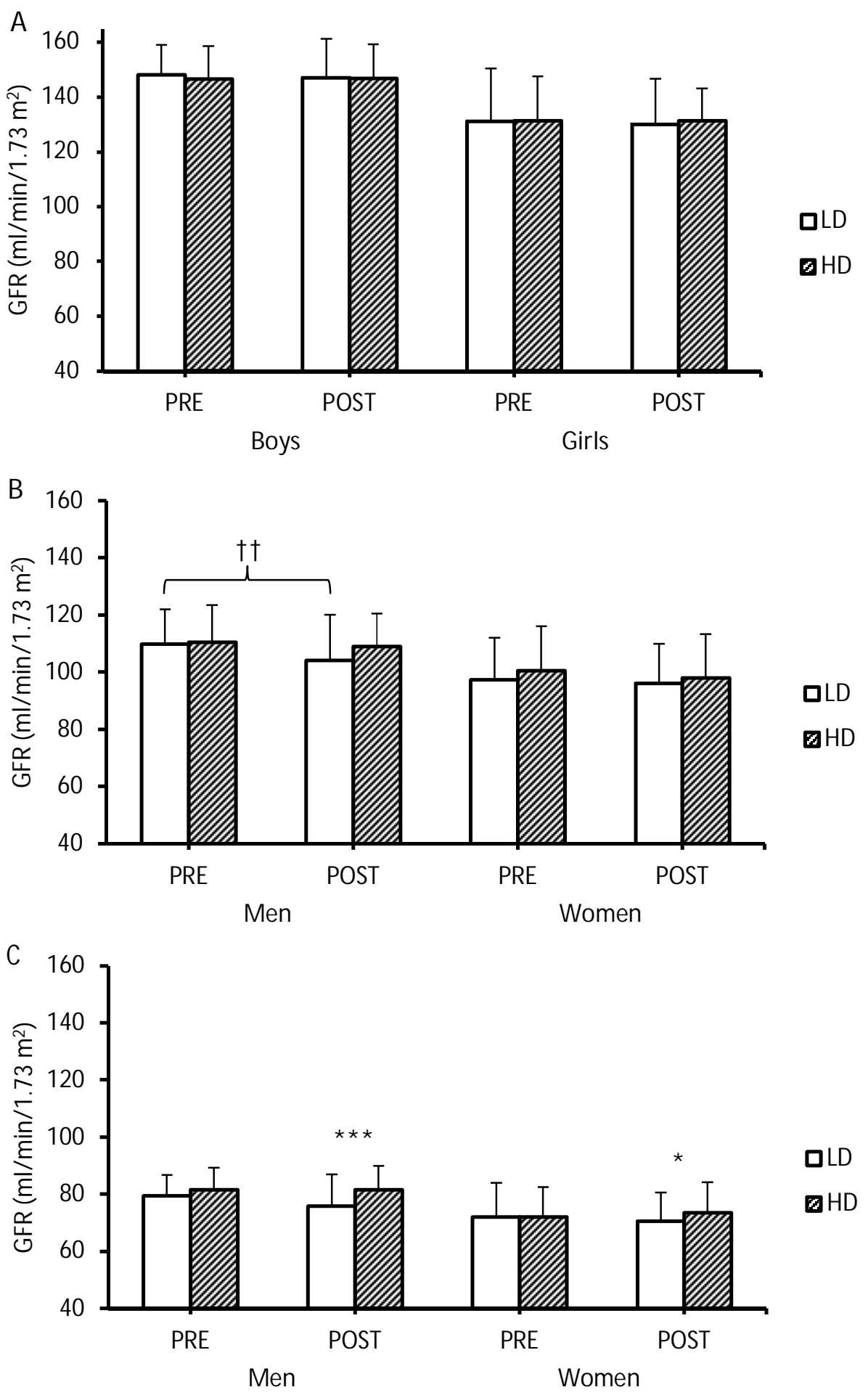

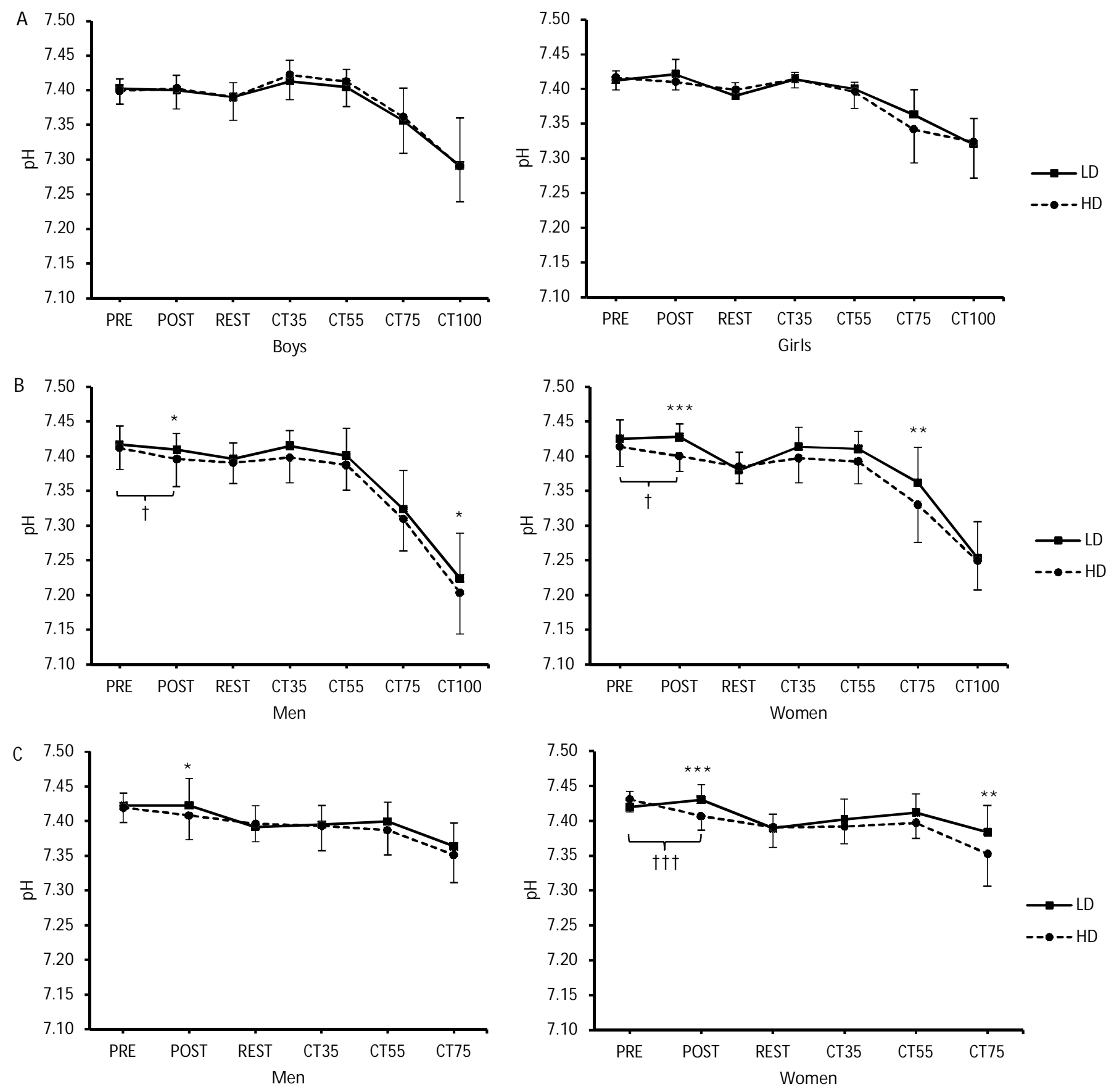

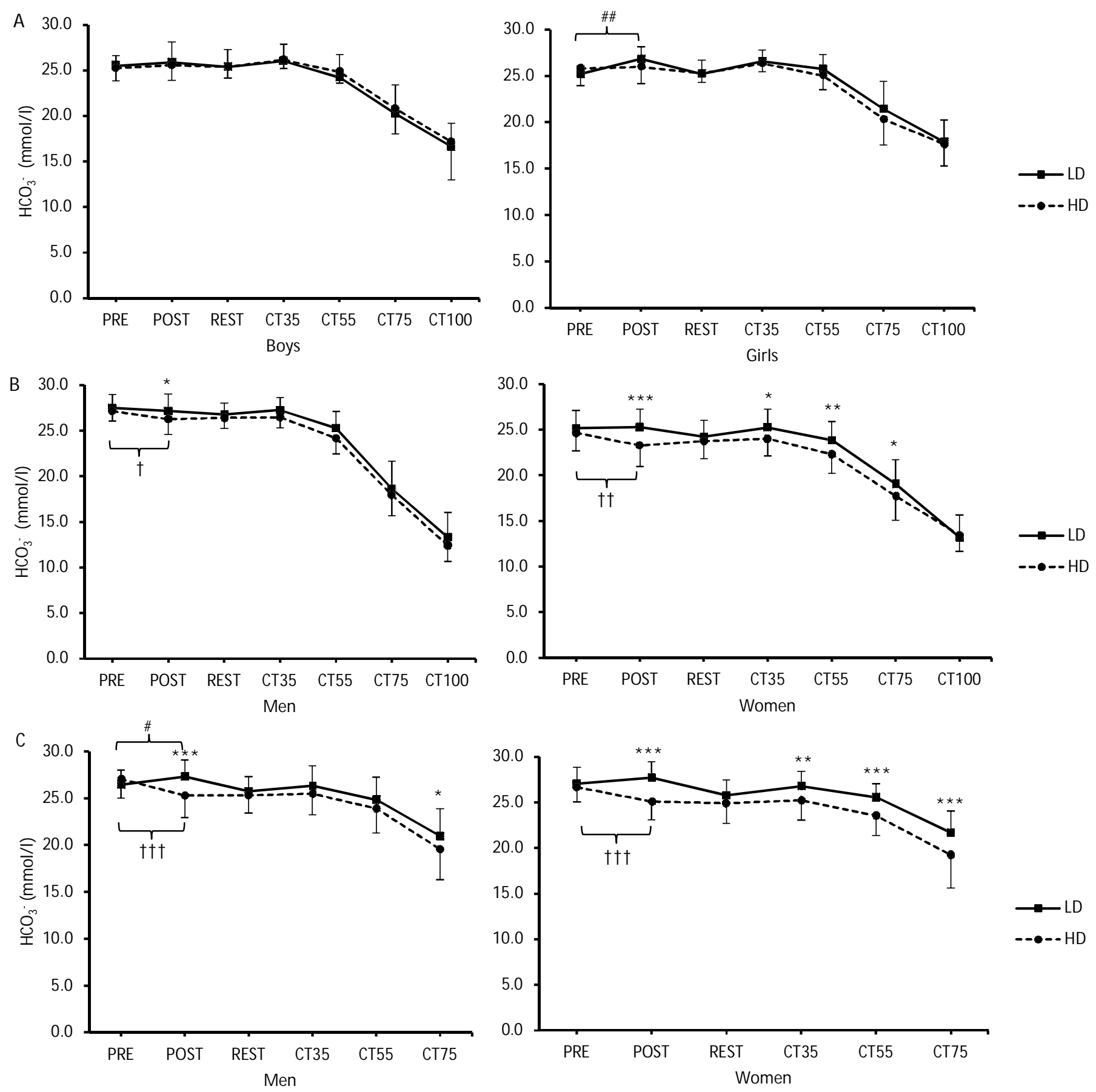

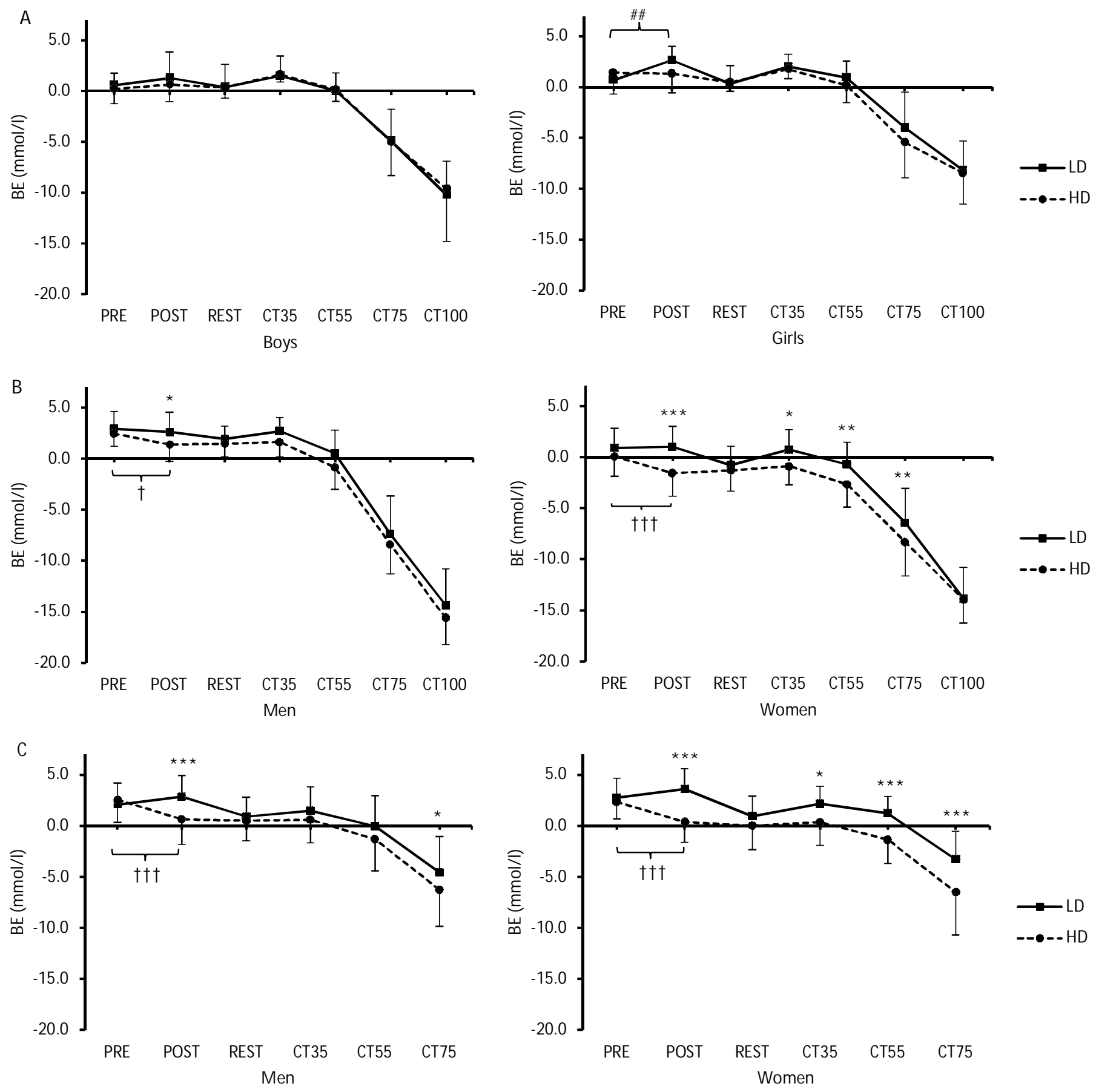

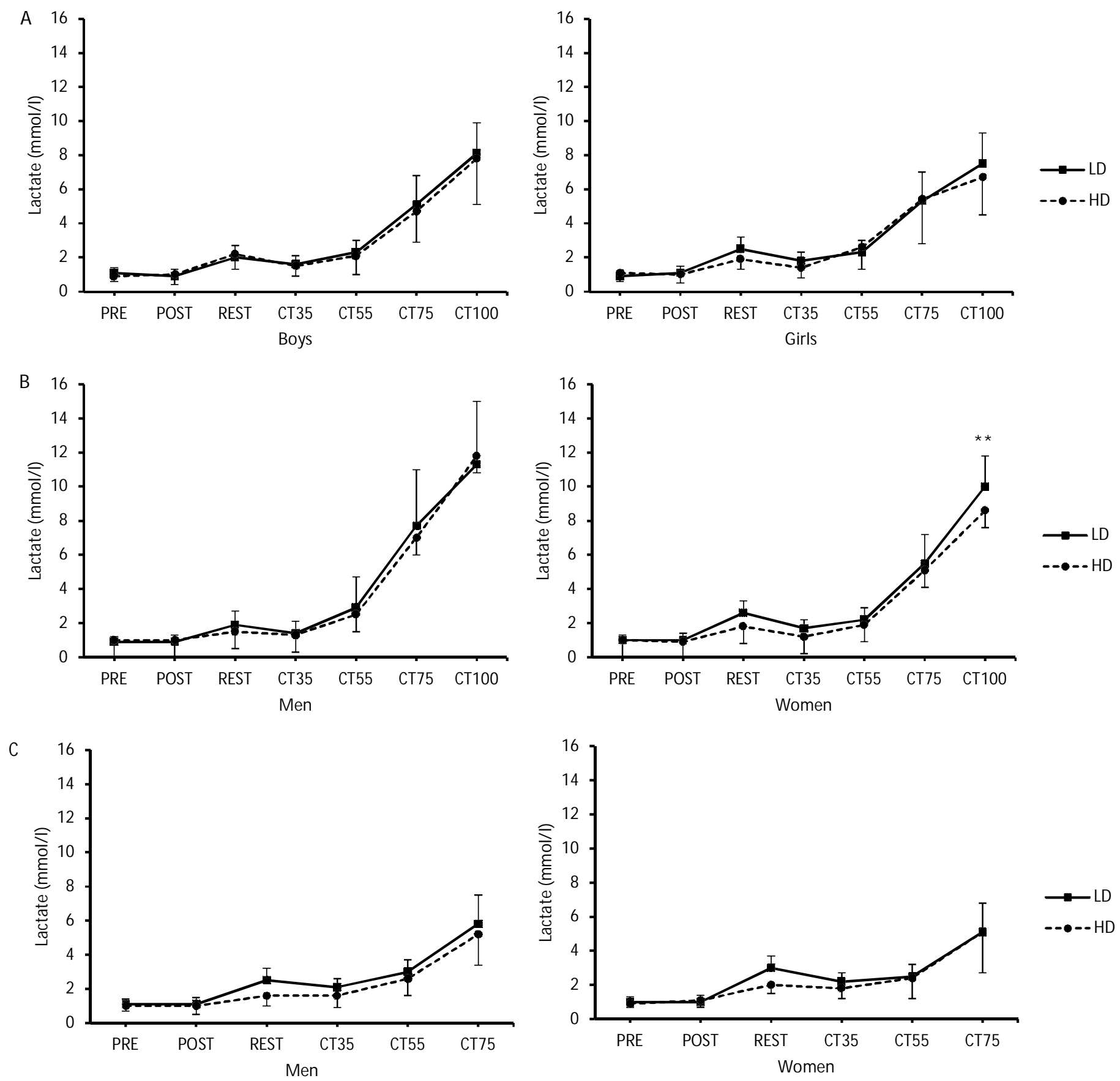